\title{
Identification of a suitable working posture for female workers engaged in golden thread work
}

\begin{abstract}
:
Background: The golden thread (jori) work is one of the major home based industries providing employment to thousands of artisans spread over several rural areas of the West Bengal. The study is essentially labor intensive and thus workers are prone to suffer from work related health problems. Objective: The present study was aimed to evaluate the musculoskeletal disorders (MSDs) and postural stress of the female golden thread workers. Methods: The study was carried on 123 adult female golden thread workers in different districts of West Bengal. The prevalence of MSD, body part discomfort rating (BPD) and postural stress (by OWAS, RULA, REBA method) of the workers were evaluated by standard methods. The EMG of shoulder and back muscle was recorded with the help of the BIOPAC system. Result: The results showed that the prevalence of MSDs, BPD rating and postural stress were comparatively lower in case of sitting on the floor with folded legs than squatting and sitting on the floor with stretched legs. The EMG and RMS values of EMG voltage of shoulder and back muscle were comparatively lower in this posture than that of other two postures. Conclusion: It was therefore, concluded that sitting on the floor with folded legs was less hazardous and it imposed less postural stress in comparison to other sitting postures adopted by the golden thread workers.
\end{abstract}

Key Words: Golden thread worker, MSD, BPD, Posture, stress, EMG
Payel Maity, Sujaya De, Amitava Pal, Hiranmoy Mahata, Mousumi Chatterjee and Prakash C. Dhara

Ergonomics and Sports Physiology Division, Dept. of Human Physiology with Community Health, Vidyasagar University, Midnapore- 721102, West Bengal, India

Corresponding Author:

Prof. Prakash C. Dhara Email: prakashdhara@rediffmail.com

c) 2014 IJOSH All rights reserved.

\section{Introduction}

Now women have become a large workforce in the production sector. It is a fact that all women work. Some of their work goes unrecognized because they do a variety of jobs daily which does not fit into any specific 'occupation'. Most of them are involved in arduous household work. Women work for longer hours and contribute substantially to family income. To understand the issue of occupational health problems of women, it is necessary to make a detailed study of the women's work in terms of the actual activity undertaken, and the hours of work.

The working condition of the workers is related to their occupational health and productivity. The working condition of women in India is currently similar to those found in early $19^{\text {th }}$ century in industrial country [1]. Decades of research have identified certain physical workplace factors that increase the risk for Musculoskeletal disorders (MSD). Perhaps nowhere is the problem of stooped and squatting postures of greater magnitude than in developing countries such as India [2]. An adaptation of such postures is frequently observed in small scale industries in India. Most of the manually energized operations in these industries are evidence of such postures. An industry is identified in central India, where operators are mostly women operators and $91 \%$ of them are suffering from work related MSDs [3].

Adoption of awkward posture in workplace may be the cause of different work related health problems of the workers. In hand driven cotton spinning operation, awkward postures in different parts of body (i.e. bent back, folded knees, bent neck) were very common. The survey revealed that among the operators, symptoms from knees, back and shoulders over the course of time were significantly more prevalent compared to other body regions [4]. A similar study on goldsmith [5] reported that the workers by adopting awkward postures at work, most often suffered from MSDs particularly affecting the low back and neck region.

Maity et al [6] investigated work related musculoskeletal disorder and postural stress on 111 brick moulders in West Bengal, India. The study revealed that primary illnesses amongst the sample 
population was essentially musculoskeletal disorders, including shoulder pain, back pain, neck pain, and knee pain.

During work the female workers are required to adopt different posture in relation to the task involved. Squatting is one of the posture patterns under the influence of the traditional lifestyle in Asian countries. Indians are found to adopt traditional sitting posture that is, sitting on the floor with folded legs. Women used to adopt such posture to perform various activities, e.g., different domestic tasks, handcrafting, different professional work, leisure activities etc.

The relationship between the worker, and the poor, ergonomically deficient work place design, forces the workers to succumb to unnatural postures. This leads to different types of musculoskeletal ailment which have been demonstrated in several studies earlier [7].

In West Bengal state a large number of women are engaged in golden thread ( in local term 'Jori') work. They stitch on the cloth ('sharees') by golden thread to make it attractive. Different predefined art designs are made on the cloth piece. The cloth piece is set in a wooden frame of certain height. The workers perform the task by sitting on the floor. Golden thread work is one of the tedious professions, requiring long hours of static work. It is also a high risk occupation for developing MSDs as awkward posture, repetitive movements, long working time and no rest pauses are common.Golden thread workers are found to adopt 3 different postures during performing the task e.g., sitting on the floor with folded legs, squatting posture, and sitting on the floor with stretched legs.

In spite of the national and international importance of the handloom with golden thread work, there have almost no ergonomics studies on golden thread workers. The present study has therefore, been carried out in this home industry with the objectives of identifying a suitable work posture for female workers.

\section{Methods}

Selection of site: The study was conducted on female golden thread workers in different districts of West Bengal, viz., Purba Medinipur and Paschim Medinipur in India. The selection of these districts was made because a significant part of the female population is engaged in golden thread work in these districts.

Selection of Subject: The study was carried on 123 adult women workers having the age range of $18-60 \mathrm{yrs}$, who were engaged in golden thread work. The subjects were selected at random from different areas of Purba and Paschim Medinipur districts in West Bengal. All of them volunteered for the study. The subjects having at least 4 years of working experience in the present occupation was one of the inclusion criteria. The research protocol of the study was approved by the institutional ethical committee. The subjects were further divided into three sub-groups on the basis of the posture(s) they adopted during work. The job-work profile of the workers put them working in these three postures, a) sitting on the floor with folded legs
(Fig.1), b) squatting posture (Fig.2), and c) sitting on the floor with stretched legs (Fig.3).

Body Mass Index (BMI): Body Mass Index (BMI) is the gold standard to be used in adults to assess the nutritional and anthropometric status of the workers [8] and it can be used in monitoring anthropometric changes and disease risk analysis for the population [9]. The BMI was computed by the following formula (Park 2005): BMI = Weight $(\mathrm{kg}) /$ Height $^{2}(\mathrm{mt})$.

Evaluation of the musculoskeletal disorder: The prevalence of musculoskeletal disorder (MSD) of the female workers performing golden thread work was evaluated by using modified 'Nordic' questionnaire [10] during adopting the following sitting postures: sitting on the floor with folded legs, squatting posture, and sitting on the floor with stretched legs.

Body Part Discomfort (BPD) rating: The intensity of pain or discomfort in different body segments was assessed by a 10 point scale which was a modified pain mapping scale of Wilson and Corlette, [11]. The scale was graded from no discomfort at all to maximum discomfort. The discomfort was assessed in three sitting postures, i.e., sitting on the floor with folded legs, squatting, and sitting on the floor with stretched legs.

Twelve body segments were assessed in this study. The overall discomfort level was computed as the mean of the individual discomfort level assessed at various body segments. According to the degree of severity, the scores of the 10-point scale were divided into three subgroups [12], i.e., mild (1-4), moderate ( $>4$ $-<7$ ) and severe (>7).

\section{Evaluation of Postural Stress:}

- Postural analysis: Various techniques have been applied for postural analyses to identify the stress of the work. Working postures were evaluated by OVAKO Working postures Analysis System (OWAS) method [13]. Though OWAS method has a wide range of use but the results can be low in detail. Therefore, Rapid Upper Limb Assessment (RULA) [14] and Rapid Entire Body Assessment (REBA) methods [15] were also applied for analysis work posture of the workers. The postures were chosen from the working images recorded with camera (Sony Handycam and Nikon SLR). When taking pictures of working postures, the camera was positioned at a suitable angle to the operator so that three-dimensional working postures could be identified during playback. The selected postures used in this study were those that the field observers classified as stressful to the human musculoskeletal system.

- EMG Study: The EMG of the shoulder (trapezious) and back (latissimus dorsi) muscles of female golden thread workers was recorded with the help of the BIOPAC system (USA). This laboratory study was carried out on 10 randomly chosen female workers amongst previously selected subjects. The random selection was made according to the alphabetical order of the name of the selected subjects. The subjects were asked to sit in normal Indian traditional sitting posture on the floor which was taken as reference posture. Then they were asked to work in three different working postures, i.e., sitting 
on the floor with folded legs, squatting posture, and sitting on the floor with stretched legs. The EMG was recorded in those postures.

(a) Muscle selection: The subjective evaluation pointed out that the prevalence of pain or discomfort was in the shoulder and lower back regions of the body. For that reason, Trapezious, a muscle of the shoulder and Latissimus dorsi, a muscle of the lower back were specifically selected for EMG study.

(b) Subject preparation: At first subjects were asked to wear minimum clothing, so that the muscle could be detected by anatomical landmark system, based on dominant bone areas and prominences or other structures that can easily be palpated from dorsal plane of body.

Then skin preparation was done by soft rubbing it with a very fine sand paper to remove dead skin, sweat and dirt. When the skin typically turned into a light red color, it was said to be in good impedance condition. After the skin preparation, silver/ silver chloride pre-gelled; disposable electrodes were placed over the muscle. The diameter of the conductive area of the electrode was $1 \mathrm{~cm}$.Electrodes were attached along the direction of the muscles fibers of the muscle. Three electrodes were placed in the required muscle with $2 \mathrm{~cm}$ of inter-electrode gap (center point to center point). Then the leads (SS2L) were attached to electrodes. One of them was used for positive signal, another for negative signal and the rest was neutral.

(c) Analysis of EMG value: EMG signals were recorded in the frequency range of $5-1000 \mathrm{~Hz}$. The absolute EMG and the rootmean-square (RMS) values were computed by using BSL Pro 3.7 software of BIOPAC system. Thelength of epochs for calculating the absolute EMG and the root-mean-square (RMS) was set in $1 \mathrm{sec}$ by setting the Delta $\mathrm{T}$.

Statistical Analysis: Data were summarized into mean and standard deviation values using Microsoft Excel.The ANOVA study, Chi square test and Post-hoc analysis were made using the ORIGIN 6.1 software. Chi square test was performed for analyzing data of questionnaire study (MSD). ANOVA and Post-hoc analysis were done for the results of EMG study.

\section{Results}

The general physical characteristics, i.e., the height and weight of the golden thread workers have been presented in Table 1. The average age, height and weight of the subjects were 24.50 years, $150.59 \mathrm{~cm}$ and $46.52 \mathrm{~kg}$ respectively. The age range of the subjects was 18 to 60 years. The average BMI was $20.48 \mathrm{Kg} /$ $\mathrm{m}^{2}$ which were within the normal range according to the cutoff value of WHO [16].

The results of different parameters studied were analyzed for three sitting postures, viz., sitting on the floor with folded legs, squatting, and sitting on the floor with stretched legs on a comparative basis.

The prevalence of musculoskeletal disorders (MSD) of the female golden thread workers in different sitting postures has been presented in Table-2. Significant differences in MSD were observed among different postures $(p<0.001)$, according to the Chi square values, in most of the body segments. The results revealed that the prevalence of MSD in case of adopting squatting posture and sitting on the floor with stretched leg was comparatively higher in most of the body segments than that of sitting on the floor with folded legs excepting the neck, upper back and thigh segments. Those workers who adopted squatting posture had higher prevalence of pain in shoulder, elbow, wrist, upper back, lower back, and feet compared to other two working postures.

Table I : Physical characteristics of female golden thread workers $(n=123)$

\begin{tabular}{|ccc|}
\hline Parameters & Mean \pm SD & Range \\
\hline Age $(\mathrm{yrs})$ & $24.50 \pm 7.45$ & $18-50$ \\
\hline Height $(\mathrm{Cm})$ & $150.59 \pm 4.23$ & $138.2-161.1$ \\
\hline Weight $(\mathrm{Kg})$ & $46.52 \pm 6.48$ & $31.0-61.0$ \\
\hline $\mathrm{BMI}\left(\mathrm{Kg} / \mathrm{m}^{2}\right)$ & $20.48 \pm 2.45$ & $14.70-26.90$ \\
\hline
\end{tabular}

The quantitative assessment of the perceived rating of discomfort of the workers was studied by using a 10-point scale and the results showed that the workers adopting different postures were suffering from different degrees of perceived exertion (Table 3). According to the degree of severity, the scores of the 10-point scale were divided into three subgroups [12], i.e., mild (1-4), severe (>4-7) and very severe (>7). It was revealed that in case of sitting on the floor with stretched legs, moderate degree of discomfort (>4 to $\leq 7$ ) was observed in upper back, middle back and shoulder and severe degree of discomfort $(>7)$ was observed in lower back whereas in squatting posture moderate degree of discomfort (>4 to $\leq 7$ ) was observed in both shoulder and lower back. In case of sitting on the floor with folded legs, moderate degree of discomfort ( $>4$ to $\leq 7$ ) was observed only in right shoulder and lower back. There were significant differences in BPD rating in upper back $(p<0.001)$, middle back $(p<0.001)$ and buttock $(p<0.05)$ when compared among three postures. The BPD rating in upper back, middle back and buttock was significantly lower ( $p<0.05$ or less) in case of sitting with folded legs than in the other two sitting postures. The overall discomfort rating was also significantly different $(p<0.01)$ among three sitting postures. The post-hoc analysis showed that the overall BPD rating was significantly lower in case of sitting with folded legs $(p<0.001)$ and in squatting posture $(p<0.05)$ than in the sitting on the floor with stretched legs.

Different postures adopted by the female golden thread workers were analyzed by different posture analysis methods, viz., OWAS, RULA and REBA and the results have been presented in Table-4. From the results of OWAS method it was found that the female golden thread workers had greater action level (3) in case of squatting posture than that other two postures indicating that the former posture needed corrective measures as soon as possible.

From the analysis of REBA method it was found that the squatting posture and sitting on the floor with stretched legs were categorized as 'very high risk' whereas sitting on the floor with 
Table II: Frequency (f) and percentage (\%) of musculoskeletal disorders (MSD) of Golden thread workers during adopting different postures

\begin{tabular}{|c|c|c|c|c|c|c|c|c|c|c|}
\hline \multirow{3}{*}{$\begin{array}{l}\text { Body } \\
\text { segment }\end{array}$} & \multicolumn{9}{|c|}{ Working Posture ( $n=114)$} & \multirow{3}{*}{$\begin{array}{c}\text { Chi Square Value } \\
\text { (x2) }\end{array}$} \\
\hline & \multicolumn{3}{|c|}{$\begin{array}{l}\text { Sitting on the floor with folded legs } \\
\qquad(n=68)\end{array}$} & \multicolumn{3}{|c|}{ Squatting ( $n=28$ ) } & \multicolumn{3}{|c|}{$\begin{array}{l}\text { Sitting on the floor with } \\
\text { stretched legs ( } n=18)\end{array}$} & \\
\hline & $f$ & $\%$ & Grade & $f$ & $\%$ & Grade & $f$ & $\%$ & Grade & \\
\hline Neck & 19 & 27.94 & 4 & 7 & 25 & 6 & 6 & 33.33 & 5 & $0.38 \mathrm{NS}$ \\
\hline Shoulder & 56 & 82.35 & 2 & 25 & 89.29 & 2 & 18 & 100.00 & 1 & $197.33^{*}$ \\
\hline Elbow & 13 & 19.12 & 7 & 7 & 25 & 6 & 12 & 66.67 & 4 & $16.11 *$ \\
\hline Wrist & 5 & 7.35 & 8 & 3 & 10.71 & 8 & 3 & 16.67 & 7 & $19.79 *$ \\
\hline Upper back & 31 & 45.59 & 3 & 9 & 32.14 & 3 & 18 & 100.00 & 1 & $56.69^{*}$ \\
\hline Lower back & 61 & 89.71 & 1 & 26 & 92.16 & 1 & 18 & 100.00 & 1 & $223.27^{*}$ \\
\hline Thigh & 14 & 20.59 & 6 & 8 & 28.57 & 5 & 3 & 16.67 & 7 & $3.05 \mathrm{NS}$ \\
\hline Knee & 17 & 25.00 & 5 & 9 & 32.14 & 3 & 6 & 33.33 & 5 & 0.79 NS \\
\hline Feet & 1 & 1.47 & 9 & 1 & 3.57 & 9 & 0 & 0.00 & 9 & $39.18^{*}$ \\
\hline
\end{tabular}

Table III: The Body part discomfort (BPD) rating (Mean \pm SD) in different segments of the body (in a 10 point scale) of female golden thread workers during adopting different sitting postures

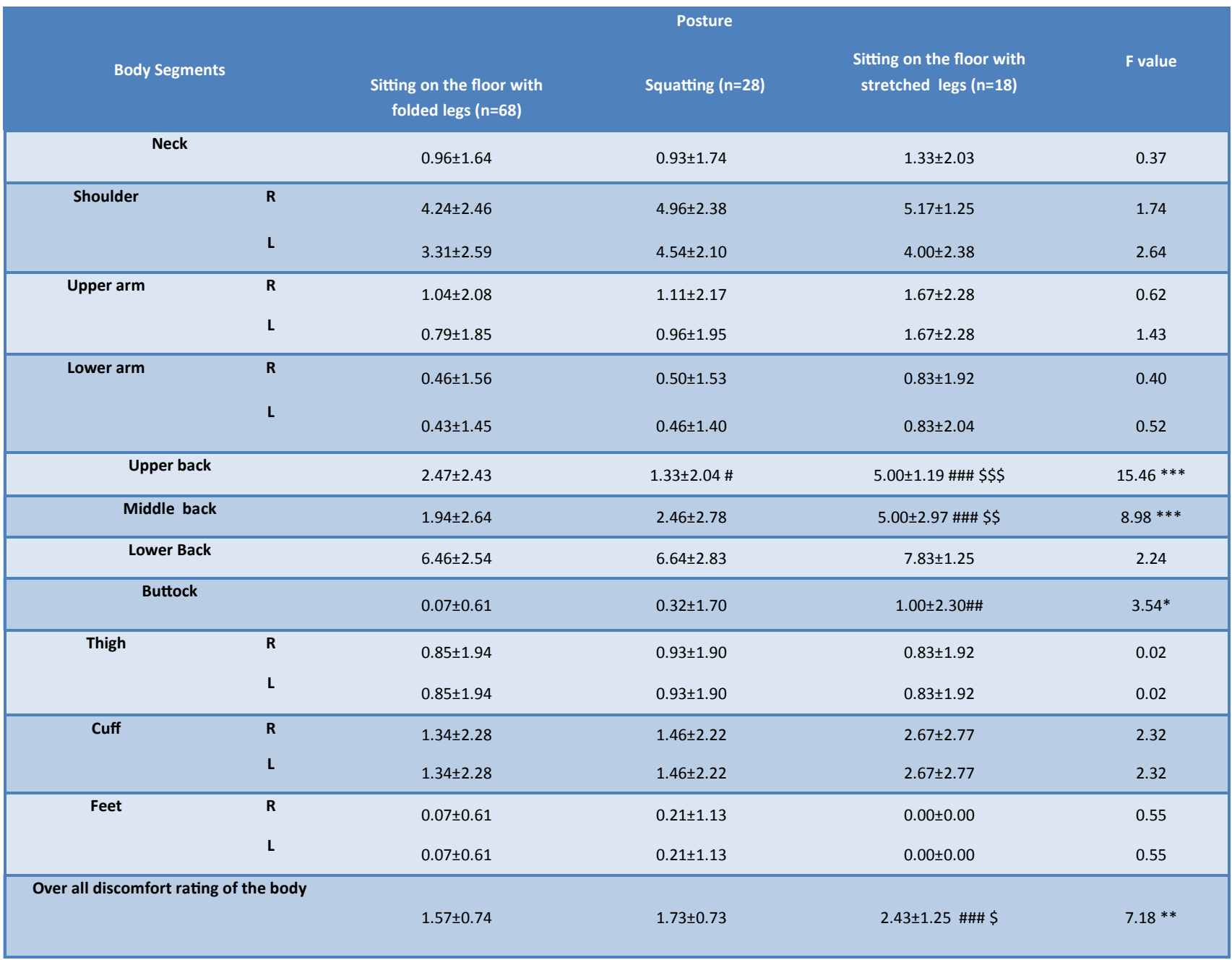


folded legs was categorized as 'high risk'. However, postural assessment by RULA method indicated that there was no difference in action level among three postures. So, from the results of postural analysis by tree methods it revealed that the workers who sat on the floor with folded legs showed lowest action level than that of other two postures.

The EMG voltages and RMS values of EMG of the shoulder (Trapezius) muscle of female golden thread workers have been presented in Table -5 . From the results of ANOVA, it was revealed that there was a significant differences ( $p<0.01$ or lesser) in the EMG values and RMS values of shoulder muscle among different sitting postures. While studying the relative percentage difference with respect to normal sitting posture, which was taken as reference posture, it was found that the deviation was the minimum in case of sitting with folded legs, except the left shoulder muscle, than that of other two postures.

A post hoc analysis of EMG and RMS value of EMG of shoulder muscle in different working postures has been presented in Table $6 \mathrm{~A}$ and $6 \mathrm{~B}$. The EMG values of right side and RMS values in both side was significantly lower $(p<0.01)$ in case of sitting on the floor with folded legs than that of squatting posture whereas a significantly lower values of EMG values in the left side $(p<0.05)$ level was observed while sitting on the floor with stretched legs than that of squatting posture. The RMS value showed significantly lower value ( $p<0.05$ or lesser) while sitting on the floor with folded legs than that of other two postures.

The EMG voltage and RMS values of back muscle (lattisimus dorsi) of the golden thread workers have been presented in Table 7. The right side EMG and both side RMS values of the same in back muscle showed a significant difference ( $p<0.05$ or lesser) amongst the postures under study. The percentage difference of EMG values from that of reference posture (normal sitting) were greater in case of squatting posture than that of other two postures. However, RMS values were the highest in case sitting on the floor with folded legs.

The results of the post hoc analysis of the EMG voltage and RMS value of back muscle in different working postures have been presented in Table $8 \mathrm{~A}$, and $8 \mathrm{~B}$ respectively. It was noted that the EMG voltage of right side was significantly higher in squatting posture and in sitting on the floor with folded legs $(p<0.05)$ when compared to values in normal sitting posture. There was no significant difference in EMG voltage between sitting on the floor with folded lags and stretched legs as well as between sitting with stretched legs and squatting posture. In case of RMS values significant differences ( $p<0.01$ or lesser) were noted between sitting on the floor with folded lags and stretched legs as well as between sitting with stretched legs and squatting posture.
Table IV : Results (action level and risk levels) of postural analysis of the golden thread workers working in different work postures

\begin{tabular}{|c|c|c|c|c|c|c|}
\hline \multirow{3}{*}{ Posture } & \multicolumn{6}{|c|}{ Postural analysis of golden thread workers } \\
\hline & \multicolumn{2}{|c|}{ OWAS } & \multicolumn{2}{|c|}{ REBA } & \multicolumn{2}{|c|}{ RULA } \\
\hline & $\begin{array}{l}\text { Action } \\
\text { Level }\end{array}$ & Risk level & $\begin{array}{l}\text { Ac- } \\
\text { tion } \\
\text { Level }\end{array}$ & Risk level & $\begin{array}{l}\text { Action } \\
\text { Level }\end{array}$ & Risk leve \\
\hline $\begin{array}{l}\text { Sitting on the } \\
\text { floor with } \\
\text { folded legs }\end{array}$ & 2 & $\begin{array}{l}\text { Correc- } \\
\text { tive } \\
\text { measure } \\
\mathrm{s} \text { in the } \\
\text { near } \\
\text { future }\end{array}$ & 10 & $\begin{array}{l}\text { High risk, } \\
\text { investi- } \\
\text { gate and } \\
\text { imple- } \\
\text { ment } \\
\text { change }\end{array}$ & 7 & $\begin{array}{c}\text { Investi- } \\
\text { gate and } \\
\text { imple- } \\
\text { ment } \\
\text { change }\end{array}$ \\
\hline $\begin{array}{l}\text { Sitting on the } \\
\text { floor with } \\
\text { stretched } \\
\text { legs }\end{array}$ & 2 & $\begin{array}{l}\text { Correc- } \\
\text { tive } \\
\text { measure } \\
\mathrm{s} \text { in the } \\
\text { near } \\
\text { future }\end{array}$ & 12 & $\begin{array}{l}\text { Very high } \\
\text { risk, } \\
\text { imple- } \\
\text { ment } \\
\text { Change }\end{array}$ & 7 & $\begin{array}{c}\text { Investi- } \\
\text { gate and } \\
\text { imple- } \\
\text { ment } \\
\text { change }\end{array}$ \\
\hline Squatting & 3 & $\begin{array}{l}\text { Correc- } \\
\text { tive } \\
\text { measure } \\
\mathrm{s} \text { as soon } \\
\text { as possi- } \\
\text { ble }\end{array}$ & 12 & $\begin{array}{c}\text { Very high } \\
\text { risk, } \\
\text { imple- } \\
\text { ment } \\
\text { Change }\end{array}$ & 7 & $\begin{array}{c}\text { Investi- } \\
\text { gate and } \\
\text { Imple- } \\
\text { ment } \\
\text { change }\end{array}$ \\
\hline
\end{tabular}

\section{Discussion}

Body weight and height are normally used as an indicator of an individual's health. Efforts were also made to evaluate the nutritional status of the subjects by anthropometric data. Anthropometric index like body mass index (BMI) is the simple, safe, inexpensive method [17] and useful indicator for the nutritional assessment [18]. It may be noted from the study that the average values of $\mathrm{BMI}$ of the subjects were approximately within the normal range $\left(20.48 \mathrm{Kg} / \mathrm{m}^{2}\right)$. The work related musculoskeletal disorders are defined as a musculoskeletal injury that results from hazardous work postures. From the present study it was found that the prevalence of MSD was high in some of the body segments of golden thread weavers, viz, shoulder (100\%), elbow $(66.67 \%)$, upper back (100\%), lower back (100\%), and neck $(33.33 \%)$. A similar study was conducted on carpet weavers by Choobineh et al [19] who studied the prevalence of MSD symptoms in different body regions and showed that shoulders $(47.8 \%)$, lower back $(45.2 \%)$, wrists $(38.2 \%)$, upper back $(37.7 \%)$, neck $(35.2 \%)$ and knees $(34.6 \%)$ were the most commonly affected regions among the weavers. Metgud et al. [20] also studied on the MSD of women workers in a woolen textile factory and reported occurrence of pain in the lower back (47\%) and neck (19\%). In a study on handloom weavers [21] it was reported that the occurrence of MSD was high in lower back (75\%), upper back (73.4), shoulder $(68 \%)$, elbow (65\%), wrist $(70.3 \%)$, and neck $(57.8 \%)$. It may be noticed that the prevalence of MSD was very high in back, elbow, shoulder, and neck where workers were performing weaving type of task. It may be pointed out that the occurrence of pain in different segments of the body in the present study was higher than that of other studies. The higher prevalence of work related MSD in different segments of the body of the workers might be due to use of 
Original Article / IJOSH/ ISSN 2091-0878

Table V : Mean and standard deviation of EMG and RMS values $(\mathrm{mV})$ of shoulder muscle of golden thread workers adopting normal sitting (resting) and three different working postures $(n=10)$ [ $R$ and $L$ indicates right and left side of the body]

\begin{tabular}{|c|c|c|c|c|c|c|c|c|}
\hline & \multicolumn{2}{|c|}{ EMG-R } & \multicolumn{2}{|c|}{ EMG-L } & \multicolumn{2}{|c|}{ RMS-R } & \multicolumn{2}{|c|}{ RMS-L } \\
\hline Postures & Value (mV) & $\begin{array}{c}\% \\
\text { deviation }\end{array}$ & Value (mV) & $\begin{array}{c}\% \\
\text { deviation }\end{array}$ & Value (mV) & $\begin{array}{c}\% \\
\text { deviation }\end{array}$ & Value (mV) & $\begin{array}{c}\% \\
\text { deviation }\end{array}$ \\
\hline $\begin{array}{l}\text { Normal sitting } \\
\quad \text { (resting) }\end{array}$ & $\begin{array}{l}0.0264 \\
\pm 0.012\end{array}$ & - & $\begin{array}{l}0.0298 \\
\pm 0.008\end{array}$ & - & $\begin{array}{r}0.0307 \\
\pm 0.007\end{array}$ & - & $\begin{array}{l}0.0368 \\
\pm 0.008\end{array}$ & - \\
\hline $\begin{array}{c}\text { Sitting on the } \\
\text { floor with folded } \\
\text { legs }\end{array}$ & $\begin{array}{l}0.0512 \\
\pm 0.024\end{array}$ & 94.13 & $\begin{array}{l}0.0407 \\
\pm 0.044\end{array}$ & 36.60 & $\begin{array}{r}0.0473 \\
\pm 0.007\end{array}$ & 54.28 & $\begin{array}{l}0.0458 \\
\pm 0.008\end{array}$ & 24.59 \\
\hline $\begin{array}{l}\text { Sitting on the } \\
\text { floor with } \\
\text { Stretched legs }\end{array}$ & $\begin{array}{l}0.0608 \\
\pm 0.067\end{array}$ & 130.63 & $\begin{array}{l}0.0303 \\
\pm 0.037\end{array}$ & 1.43 & $\begin{array}{l}0.0913 \\
\pm 0.019\end{array}$ & 197.72 & $\begin{array}{l}0.0951 \\
\pm 0.014\end{array}$ & 158.49 \\
\hline Squatting & $\begin{array}{l}0.1061 \\
\pm 0.044\end{array}$ & 302.44 & $\begin{array}{l}0.0901 \\
\pm 0.054\end{array}$ & 201.98 & $\begin{array}{r}0.0836 \\
\pm 0.048\end{array}$ & 172.58 & $\begin{array}{l}0.0749 \\
\pm 0.032\end{array}$ & 103.54 \\
\hline F-value & $5.75^{* *}$ & - & $4.65^{* *}$ & - & $18.67^{* * *}$ & - & $19.20^{* * *}$ & - \\
\hline
\end{tabular}

Table VI A: Post-hoc analysis of EMG value of shoulder muscle of golden thread workers adopting normal sitting (resting) and three different working postures $(n=10)$ [ $R$ and $L$ indicates right and left side of the body]

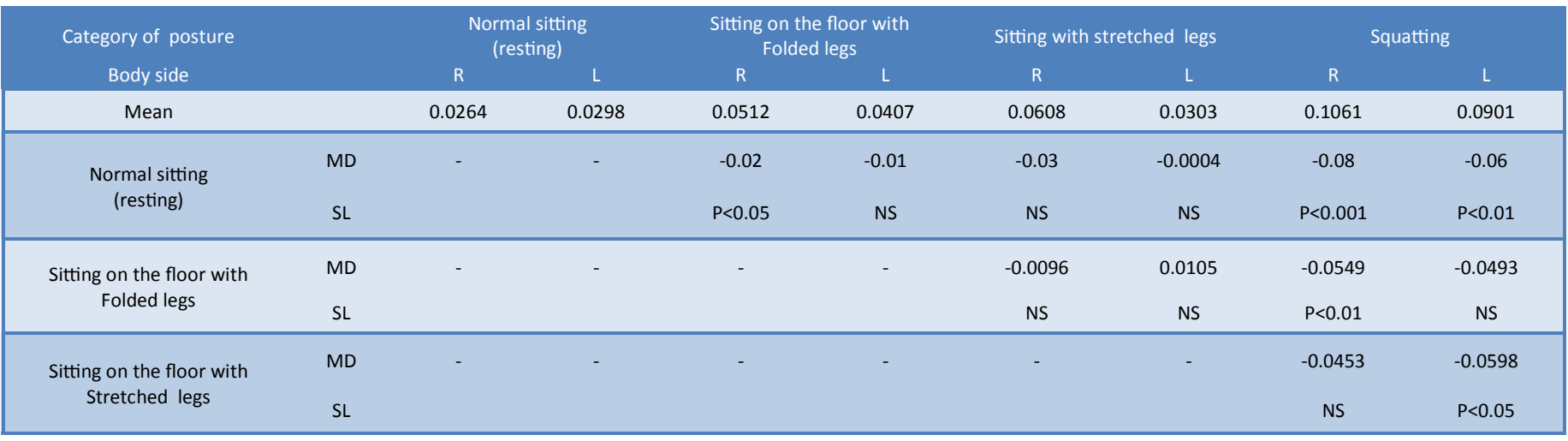

$M D=$ Mean difference, SL=Significant level

Table VI B: Post-hoc analysis of RMS value of shoulder muscle of golden thread workers adopting normal sitting and three different working postures $(n=10)$ [ $R$ and $L$ indicates right and left side of the body]

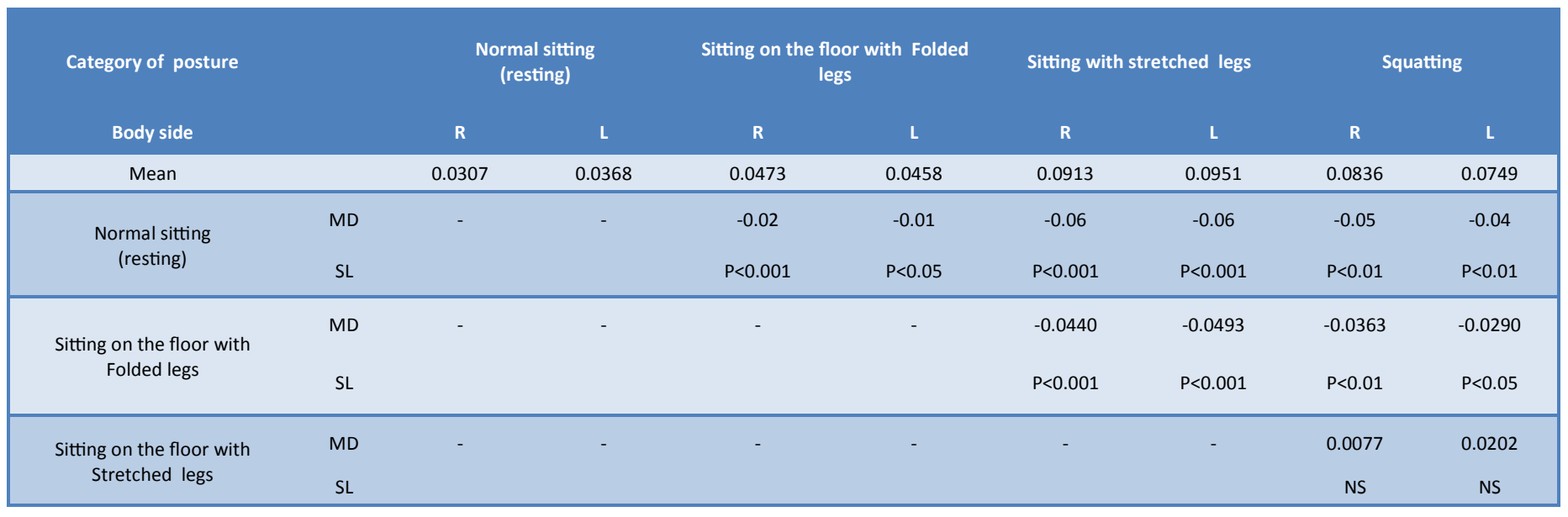


Table VII : Mean and standard deviation of EMG and RMS values ( $\mathrm{mV}$ ) of back muscle of golden thread workers adopting normal sitting (resting) and three different working postures [ $R$ and $L$ indicates right and left side of the body]

\begin{tabular}{|c|c|c|c|c|c|c|c|c|}
\hline \multirow[b]{2}{*}{ Postures } & \multicolumn{2}{|c|}{ EMG-R } & \multicolumn{2}{|c|}{ EMG-L } & \multicolumn{2}{|c|}{ RMS-R } & \multicolumn{2}{|c|}{ RMS-L } \\
\hline & Value (mV) & $\%$ deviation & Value (mV) & $\%$ deviation & Value (mV) & $\%$ deviation & Value (mV) & $\%$ deviation \\
\hline Normal sitting & 0.0234 & & 0.0258 & & 0.0265 & & 0.0315 & \\
\hline (resting) & \pm 0.006 & & \pm 0.005 & & \pm 0.006 & & \pm 0.005 & \\
\hline $\begin{array}{l}\text { Sitting on the floor with } \\
\text { folded legs }\end{array}$ & $\begin{array}{l}0.0361 \\
\pm 0.015\end{array}$ & 53.94 & $\begin{array}{l}0.0287 \\
\pm 0.017\end{array}$ & 11.15 & $\begin{array}{l}0.0857 \\
\pm 0.027\end{array}$ & 223.56 & $\begin{array}{l}0.0800 \\
\pm 0.021\end{array}$ & 153.56 \\
\hline $\begin{array}{l}\text { Sitting on the floor with } \\
\text { Stretched legs }\end{array}$ & $\begin{array}{l}0.0428 \\
\pm 0.035\end{array}$ & 53.54 & $\begin{array}{l}0.0383 \\
\pm 0.030\end{array}$ & 48.22 & $\begin{array}{l}0.0279 \\
\pm 0.010\end{array}$ & 5.34 & $\begin{array}{l}0.0262 \\
\pm 0.011\end{array}$ & 16.83 \\
\hline Squatting & $\begin{array}{l}0.0758 \\
\pm 0.049\end{array}$ & 223.40 & $\begin{array}{l}0.0642 \\
\pm 0.064\end{array}$ & 148.42 & $\begin{array}{l}0.1016 \\
\pm 0.024\end{array}$ & 283.51 & $\begin{array}{l}0.0999 \\
\pm 0.022\end{array}$ & 216.72 \\
\hline F-value & $3.825^{*}$ & & $1.69 \mathrm{NS}$ & & $28.95^{* * *}$ & & $34.86 * * *$ & \\
\hline
\end{tabular}

Table VIII A : Post-hoc analysis of EMG value of back muscle of golden thread workers adopting normal sitting (resting) and three different working postures $(n=10)$ [ $R$ and $L$ indicates right and left side of the body]

\begin{tabular}{|c|c|c|c|c|c|c|c|c|c|}
\hline \multicolumn{2}{|l|}{ Category of posture } & \multicolumn{2}{|c|}{$\begin{array}{l}\text { Normal sitting } \\
\text { (resting) }\end{array}$} & \multicolumn{2}{|c|}{$\begin{array}{l}\text { Sitting on the floor with } \\
\text { Folded legs }\end{array}$} & \multicolumn{2}{|c|}{ Stretching legs } & \multicolumn{2}{|c|}{ Squatting } \\
\hline Body side & & $\mathrm{R}$ & $\mathrm{L}$ & $\mathrm{R}$ & $\mathrm{L}$ & $\mathrm{R}$ & $L$ & $\mathrm{R}$ & L \\
\hline Mean & & 0.0234 & 0.0258 & 0.0361 & 0.0287 & 0.0428 & 0.0383 & 0.0758 & 0.0642 \\
\hline \multirow{2}{*}{$\begin{array}{l}\text { Normal sitting } \\
\text { (resting) }\end{array}$} & MD & - & - & -0.0126 & -0.0029 & -0.0193 & -0.0125 & -0.0524 & -0.0383 \\
\hline & SL & & & $P<0.05$ & NS & NS & NS & $P<0.05$ & NS \\
\hline \multirow{2}{*}{$\begin{array}{l}\text { Sitting on the floor with } \\
\text { Folded legs }\end{array}$} & MD & - & - & - & - & -0.0067 & -0.0096 & -0.0397 & -0.0355 \\
\hline & SL & & & & & NS & NS & NS & NS \\
\hline \multirow{2}{*}{$\begin{array}{l}\text { Sitting on the floor with } \\
\text { Stretched legs }\end{array}$} & MD & - & - & - & - & - & - & -0.0331 & -0.0259 \\
\hline & $S L$ & & & & & & & NS & NS \\
\hline
\end{tabular}

$M D=$ Mean difference, $S L=$ Significant leve

Table VIII B : Post-hoc analysis of RMS value of back muscle of golden thread workers adopting normal sitting (resting) and three different working postures $(n=10)$ [ $R$ and $L$ indicates right and left side of the body]

\begin{tabular}{|c|c|c|c|c|c|c|c|c|c|}
\hline \multicolumn{2}{|l|}{ Category of posture } & \multicolumn{2}{|c|}{$\begin{array}{l}\text { Normal sitting } \\
\text { (resting) }\end{array}$} & \multicolumn{2}{|c|}{$\begin{array}{l}\text { Sitting on the floor with } \\
\text { Folded legs }\end{array}$} & \multicolumn{2}{|c|}{ Stretching legs } & \multicolumn{2}{|c|}{ Squatting } \\
\hline Body side & & $\mathbf{R}$ & $\mathbf{L}$ & $\mathbf{R}$ & $\mathbf{L}$ & $\mathbf{R}$ & $\mathbf{L}$ & $\mathbf{R}$ & $\mathbf{L}$ \\
\hline Mean & & 0.0265 & 0.0315 & 0.0857 & 0.0800 & 0.0279 & 0.0262 & 0.1016 & 0.0999 \\
\hline \multirow{2}{*}{$\begin{array}{l}\text { Normal sitting } \\
\text { (resting) }\end{array}$} & MD & - & - & -0.0592 & -0.0484 & -0.0014 & -0.0053 & -0.0751 & -0.0684 \\
\hline & SL & & & $P<0.001$ & $P<0.001$ & NS & NS & $P<0.001$ & $P<0.001$ \\
\hline \multirow{2}{*}{$\begin{array}{l}\text { Sitting on the floor with } \\
\text { Folded legs }\end{array}$} & MD & - & - & - & - & 0.0578 & 0.0537 & -0.0159 & -0.0199 \\
\hline & SL & & & & & $P<0.001$ & $P<0.001$ & NS & NS \\
\hline \multirow{2}{*}{$\begin{array}{l}\text { Sitting on the floor with } \\
\text { Stretched legs }\end{array}$} & MD & - & - & - & - & - & - & -0.0737 & -0.0737 \\
\hline & SL & & & & & & & $P<0.01$ & $P<0.01$ \\
\hline
\end{tabular}


significant force, repetitive movements and longer duration of exposure [22]. Caicoya and Delclos [23] stated that those perform highly repetitive tasks for longer duration has reported pain at different segments of their body. Abnormal posture creates a strain on ligaments and muscles that indirectly affects the curvature of the lumbar spine. Chronic low back pain affects the lower lumbar spine and limits the maximal range of lumbar extension [24]. Nag et al. [7] studied the work stresses of women who were engaged in sewing machine operation in small garment manufacturing units in India. They found that high prevalence of discomfort and pain in different body parts. About $68 \%$ of the women complained of back pain, among which $35 \%$ reported a persistent low back pain.

The results of the BPD rating revealed that there was a higher degree of pain in lower back and shoulder among the female workers. The high prevalence of pain was also noted on those segments of the female workers. Bandopadhyay and Sen [25] also reported severe (Garde 3) pain in different body segments of women workers due to adopting awkward sitting posture for a long time during work. Other investigators [26, 27] also reported high degree of low back pain among a large percentage $(70 \%)$ of female brick workers due to awkward working posture for prolonged period of time. Dewangan et al [28] observed maximum work related BPD at lower back among the female agricultural workers. A study by Desai [29], on women in small scale industries also showed a significantly higher body pain and discomfort, attributable to their prolonged sitting postures. While comparing three sitting postures, the extent of pain was the lowest in most of the body segments in case of sitting on the floor with folded legs. The overall discomfort / pain, considering all body segments studied, was also significantly lower during sitting on the floor with folded legs. Thus the findings of the comparison indicated that the female workers had lesser extent of pain / discomfort while sitting on the floor with folded legs.

Postural analysis by OWAS, RULA and REBA method indicated that the workers adopting squatting posture showed highest degree of risk level whereas the workers adopting sitting on the floor with folded legs posture showed lowest degree of risk level. Such findings might be related to postural stress owing to long term adoption of squatting and squat bending posture during performing the tasks. Other investigations suggested that working in squatting and squat bending posture and in same awkwardly position were both significantly associated with prevalence of lower back problem and both were judged by workers to be the most problematic job factors contributing to pain and injury [6,30,31]. Pal et al [32] evaluated postural stress of female cultivators by OWAS, RULA, QUC and REBA methods while performing potato harvesting task and observed high postural stress due to adopting squatting posture. Other investigators $[33,4]$ also found that the female workers engaged in squatting posture for prolonged period of time had high scores of OWAS , RULA and REBA indicating high risk of postural stress. Sahu and Set [27] categorized the postures adopted by the female brick moulders as having 'high' to 'very high' risk levels according to the OWAS and REBA methods.

Borah et al. [35] studied on women workers engaged in cashew nut processing industry and observed that the workers had high prevalence of MSDs due to adoption of unnatural squatting posture on the ground for a long time. Workers reported complaints about musculoskeletal problems after adopting the squatting posture since they were supported with non-suitable facilities [36, 37].

Electromyographic signal (EMG) analysis can provide information as to the relative amount of muscular activity an exercise requires, as well as the optimal positioning for the exercise [38].The EMG study of the shoulder (Trapezius) and back (Lattisimus dorsi) muscles of the female golden thread workers indicated different extent of muscular activities in three sitting postures.

The EMG voltage of shoulder muscle was the minimum in case of the workers sitting on the floor with folded legs among three working postures and in this posture minimum deviation of the EMG voltage from that of the reference posture was also noted in the dominant hand, i.e., right hand. In case of left hand the minimum EMG voltage or deviation of EMG voltage from the reference position was noted during sitting with stretched leg. This might be due to the fact that the left hand remained in the lower side of the work surface under working condition and it had a supporting role for weaving golden thread. The EMG voltage of the right side was greater than that of left side. A greater relative amplitude of an EMG signal of a muscle is associated with greater relative contractile force [39]. Salvendy [40] had shown that the degree of forward shoulder flexion, or reach, significantly influences muscular fatigue, noting that as the horizontal distance was increased, the onset of fatigue was more rapid.

On the other hand the results of EMG study of back muscle (lattisimus dorsi) indicated that back muscle had lesser myoelectric activities while sitting on the floor with folded legs in comparison to other two postures. This might be due to lesser stress imposed on the back muscle during performing the task. The stress on the back muscle depends on the degree of forward bending, twisting and instability of the body. As there was a wider base contact area of the body with the ground the worker was more stable during sitting on the floor with folded legs than that in squatting posture [12]. Further, there was lesser degree of bending of the trunk during sitting on the floor with folded leg in comparison to work under squatting posture. Those might be the probable reasons for imposing lesser stress on back muscle during sitting on the floor with folded legs. Bidard et al. [41] also revealed that the stabilization effort was greater for unsupported sitting than for standing because of not optimal alignment of the centers of mass. Thus in squatting posture more stabilizing efforts might be adopted by the body than that of sitting on floor, which possessed large contact area with the ground. Therefore, it might be one of the reasons for the lesser BPD rating (Table 2) and lower prevalence of MSD (Table 1) at the lower back region while sitting on the floor with folded legs than in that of the squatting postures. 
SEMG has been used in numerous settings to measure voltage output of relative muscle recruitment, in ergonomic analyses when comparing musculoskeletal stress in a specific muscle(s) associated with postures and to evaluate the efficacy of ergonomic interventions [42, 43]. Van Dieen et al. [44] who observed that trunk kinematics and back muscle EMG were strongly affected by the task performed, but not by the chair type. Kroemer and Grandjean [45], Schoberth [46], Zacharkow [47], and Pheasant [48] believed that sitting postures put more load on the spinal discs than standing postures. Kimura et al. [49] also found that biomechanical axial stress for the intervertebral disc increased most at L4- L5 due to a decrease in a disc height in upright posture. This might be a reason for higher muscular activity of back muscle of the workers dung working in squatting posture in comparison to working in sitting on the floor. Therefore, it was revealed from the EMG study that the muscular stress in shoulder and lower back muscles was lesser in case of sitting on the floor, especially when legs were folded, than that of squatting posture.

\section{Conclusion}

During performing tasks, the female golden thread workers had lesser prevalence of MSD, lesser extent of BPD rating, lower postural stress, and smaller myoelectric activities in shoulder and muscles while sitting on the floor with folded legs than that of sitting on the floor with stretched leg and squatting posture. So, sitting on the floor with folded legs, a traditional Indian sitting posture may be the suitable working posture for the female golden thread workers.

\section{References}

1. Kaila HL. Occupational Health for women. Indian J Occup Health 2000, 43:109-16.

2. Ergonomic interventions for reducing musculoskeletal disorders: an overview, related issues and future directions. Report May 1998. Waterloo: Institute for Work \& Health, 1998.

3. Metgud D. C., Khatri S, Mokashi M. G., Saha P. N. An ergonomic study of women workers in a woolen textile factory for identification of health related problems. Indian Journal of Occupational and Environmental Medicine 2008, 2 (1):1419.

4. Ikhar D, Deshpande V. S. Intervention of Ergonomics in Hand Driven Cotton Spinning Operation, International Journal of Ergonomics (IJEG) 2011, 1 (1) :12-19.

5. Ghosh T., Das B., Gangopadhyay S. Work-related Muskuloskeletal Disorder: An Occupational Disorder of the Goldsmiths in India, International Journal of Community Medicine 2010, 35(2): 321-325.

6. Maity P., Pal A. and Dhara P. C. Evaluation of Work Related Musculoskelital Disorder and Postural Stress of brick Kiln Workers during Performing Different Brick Making Task. In the proceedings of HWWE: Ergonomics for rural development. Vidyasagar University, Midnapore, $4^{\text {th }}-6^{\text {th }}$ December
2013, pp 386-398.

7. Nag A., Dorai H. and Nag P.K. Work stress of women in sewing machine operation, J. of Human Ergology 1992, $21: 47-55$.

8. Dorlencourt F., Priem V. and Legros D. Anthropometric indices used for the diagnosis of malnutrition in adolescents and adults: review of the literature. Bull SocPatholExot 2000, 93(5): 321-324.

9. Muñoz A.M., Falque-Madrid L., Zambrano R.C. and Maestre G.E. Basic anthropometry and health status of elderly: findings of the maracaibo aging study. J Aging Health 2010, 22(2): 242-261.

10. Kuorinka I., Jonson B., Kilbom A., Vinterberg H., BieringSorenson F., Anderson G. and Jorgensen K. Standardized Nordic questionnaire for the analysis of musculoskeletal symptoms. Applied Ergonomics 1987, 18: 233-237.

11. Wilson JR and Corlette EN. Evaluation of human work- a practical ergonomics methodology. Taylor and Francis, London; 1985.

12. Dutta S. and Dhara P. C. Evaluation of Different Sitting Postures of Rural Primary School Boys in the Classroom. Journal of Ergonomics 2012, 2:2-7.

13. Heinsalmi P. Method to measure working posture loads at working sites (OWAS). In: The Ergonomics of Working Postures. Corlette, Wilson and Manenica (Eds). Taylor and Francis, London; 1986, 100-104.

14. McAtamney L. and Corlett E.N. RULA: A survey method for the investigation of work related upper limb disorder. Applied Ergonomics 1993, 24(2):91-99.

15. Hignett S. and McAtamney L. Rapid Entire Body Assessment (REBA). Applied Ergonomics 2000, 31: 201-205.

16. WHO/IOTF/IASO. The Asia-Pacific perspective: Redefining Obesity and its Treatment. Hong Kong: World Health Organization, International Obesity Task Force, International Association for the Study of Obesity, 2000.

17. Gelber C., Hochberg C., Mead A., Wang N.Y., Wigley $\mathrm{M}$. and Klag J. Body mass index in young men and the risk of subsequent knee and hip osteoarthritis. J Med 1999, 107: 542-548.

18. Lee R. D. and Nieman N.C. Nutritional Assessment. New York: McGraw Hill 2003.

19. Choobineh A, Lahmi M, Shahnavaz H, Jazani RK, Hosseini M. Musculoskeletal Symptoms as Related to Ergonomic Factors in Iranian Hand-Woven Carpet Industry and General Guidelines for Workstation Design. International Journal of Occupational Safety and Ergonomics (JOSE) 2004, 10 (2): 157-168.

20. Metgud D. C., Khatri S, Mokashi M. G., Saha P. N., An ergonomic study of women workers in a woolen textile factory for identification of health related problems, Indian Journal of Occupational and Environmental Medicine 2008, $2(1): 14-19$. 
21. Naz H, Kwatra S., Ojha P. Prevalence of musculoskeletal disorders among handloom weavers of Uttarakhand: an ergonomic study. J. Appl. \& Nat. Sci., 20157 (1) : 101 - 104

22. Chaffin D.B., Andersson G.B.J. and Martin B.J. Occupational Biomechanics. (4 ${ }^{\text {th }}$ ed), Wiley-Interscience; New York, 2006.

23. Caicoya M. and Delclos G. L. Work demands and musculoskeletal disorders from the Spanish National Survey. Occup Med 2010; 60(6): 447-450.

24. Evcik D. and Yucel A.: Lumbar lordosis in acute and chronic low back pain patients. Rheumatol Int., 2003, 23(4):163-5.

25. Bandyopadhyay B , Sen D. Occupational Stress among Women Moulders: A Study in Manual Brick Manufacturing Industry of West Bengal. International Journal of Scientific and Research Publications, 2014, 4 (6):2250-3153

26. Das B., An evaluation of low back pain among female brick field workers of West Bengal, India. Environ Health Prev Med. 2015, 20(5):360-368.

27. Shau $S$ and Sett M .. Ergonomic evaluation of tasks performed by female workers in the unorganized sectors of the manual brick manufacturing units in India. Ergonomics SA, 2010, 22(1): 1-16.

28. Dewangan K.N., Owary C., Gogoi G. and Gorate D.U., Ergonomic Evaluation of Sickles for Paddy Harvesting by Female Agricultural Workers. In the Proceedings of Humanizing Work and Work Environment, 2007,CIAE, Bhopal, 2, pp 58-63

29. Desai V., "Small Scale Industries and Entrepreneurship", Himalaya Publishing House, 2004,Nagpur, India, Chap 1.

30. Roffey D.M., Wai E.K., Bishop P. and Dagenais. B.K.S.Causal assessment of awkward occupational postures and low back pain: results of a systematic review. Spine 2010, 10(1): 89-99.

31. Merlino L.A., Rosecrance J.C., Anton D. and Cook T.M. Symptoms of musculoskeletal disorders among apprentice construction workers. Appl Occup Environ Hyg 2003, 18 (1):57-64.

32. Pal A, De S, Sengupta P, Maity P and Dhara P C : Evaluation of Work Related Musculoskeletal Disorder and Postural Stress among Female Potato Cultivators in West Bengal, India, Ergonomics SA, 2015,27(1).

33. Bandyopadhyay B , Sen D., Occupational Stress among Women Moulders: A Study in Manual Brick Manufacturing Industry of West Bengal. International Journal of Scientific and Research Publications, 2014, 4 (6):2250-3153

34. Das B., An evaluation of low back pain among female brick field workers of West Bengal, India. Environ Health Prev Med. 2015, 20(5):360-368.

35. Borah S. and Baruah M. Musculoskeletal disorder of women workers engaged in cashew nut processing industry. In the proceedings of HWWE: Humanizing work and work environment: College of Home Science, Pantnagar, Uttarakhand, 2014, pp 536-543

36. Manuaba A., Different feature of work systems in Indonesia and their consequent approaches. J. Human Ergol., 1997, 26: 99-105.

37. Tirtayasa, K, Adiputra, IN, and Djestawana, IGG The change of working posture in manggur decrease cardiovascular load and musculoskeletal complaints among Balinese gamelan craftsmen. J. Human Ergol., 2003, 32: 71-76.

38. Richard, A.E., Robert, A.D., Kenji, C.C. Electromyographic Analysis of Core Trunk, Hip, and Thigh Muscles During 9 Rehabilitation Exercises. Journal of Orthopaedic \& Sports Physical Therapy 2007, 37(12): 754-62.

39. Neumann D. Kinensiology of musculoskeletal system foundation for rehabilitation. Mosby Elsevier , Missouri , 2010.

40. Salvendy, G. Handbook of Human Factors and Ergonomics: 2nd edition. New York, NY, John Wiley \& Sons, 1997, pp 245-249.

41. Bidard C., Rienstra S., Veltink P.H., Koopman H.F.J.M., Grady J., De Vries J., Huttenhuism L., Trunk stability while standing or sitting: a static analysis, IFESS 2000 Conference at Aalborg University, Denmark, 2000.

42. Aaras, A. Relationship between trapezius load and the incidence of musculoskeletal illness in the neck and shoulder. International Journal of Industrial Ergonomics. 1994;14: 341 -348 .

43. Marras, W. Industrial Electromyography. International Journal of Industrial Ergonomics.1990; 6:89-93.

44. Van Dieen J.H., De Looze M.P., Hermans V., Effects of dynamic office chairs on trunk kinematics, trunk extensor EMG and spinal shrinkage, Ergonomics, 2001, 44(7), 73950.

45. Kroemer K.H.E., Grandjean E., Fitting the task to the human, Taylor and Francis, London, 1997.

46. Schoberth H., Orthopaedie des Sitzens, Springer Verlag, Berlin, 1989.

47. Zacharkow D., Posture: Sitting, Standing, Chair Design and Exercise, Charles Thomas, Springfield, USA, 1988.

48. Pheasant S., Body space: Anthropometry, Ergonomics and Design, Taylor \& Francis, London, 1986.

49. Kimura S., Steinbach G.C, Watenpaugh D.E., Hargens A.R., Lumbar spine disc height and curvature responses to an axial load generated by a compression device compatible with magnetic resonance imaging, Spine, 2001, 26, 2596-2600. 